\title{
When True Recognition Suppresses False Recognition: Evidence from Amnesic Patients
}

\section{Citation}

Schacter, Daniel L., Mieke Verfaellie, Michael D. Anes, and Carrie Racine. 1998. When true recognition suppresses false recognition: Evidence from amnesic patients. Journal of Cognitive Neuroscience 10(6): 668-679.

\section{Published Version}

doi:10.1162/089892998563086

\section{Permanent link}

http://nrs.harvard.edu/urn-3:HUL.InstRepos:3627121

\section{Terms of Use}

This article was downloaded from Harvard University's DASH repository, and is made available under the terms and conditions applicable to Other Posted Material, as set forth at http:// nrs.harvard.edu/urn-3:HUL.InstRepos:dash.current.terms-of-use\#LAA

\section{Share Your Story}

The Harvard community has made this article openly available.

Please share how this access benefits you. Submit a story.

Accessibility 


\title{
When True Recognition Suppresses False Recognition: Evidence from Amnesic Patients
}

\author{
Daniel L. Schacter \\ Harvard University and Boston Veterans Affairs Medical Center \\ Mieke Verfaellie \\ Boston University School of Medicine and Boston Veterans Affairs Medical Center \\ Michael D. Anes \\ Boston University \\ Carrie Racine \\ Harvard University
}

\begin{abstract}
False recognition occurs when people mistakenly claim that a novel item is familiar. After studying lists of semantically related words, healthy controls show extraordinarily high levels of false recognition to nonstudied lures that are semantic associates of study list words. In previous experiments, we found that both Korsakoff and non-Korsakoff amnesic patients show reduced levels of false recognition to semantic associates, implying that the medial temporal/diencephalic structures that are damaged in amnesic patients are involved in the encoding and/or retrieval of information that underlies false recognition. These data contrast with earlier results indicating greater false recognition in Korsakoff amnesics than in control subjects. The present experiment tests the hypothesis that greater or lesser false recognition of semantic associates in amnesic patients,
\end{abstract}

\section{INTRODUCTION}

Although memory is often accurate, it is also subject to various kinds of errors and distortions (for recent reviews, see Johnson, Hashtroudi, \& Lindsay, 1993; Roediger, 1996; Schacter, 1995). Memory distortions are important because they provide insights into the constructive nature of encoding and retrieval operations. During the past several years, there has been growing interest in the brain structures and processes that are related to memory errors and distortions, as explored in experiments with various patient populations (cf. Kroll, Knight, Metcalfe, Wolf, \& Tulving, 1996; Metcalfe, Funnell, \& Gazzaniga, 1995; Moscovitch, 1995; Parkin, Binschaedler, Harsent, \& Metzler, 1996; Reinitz, Verfaellie, \& Milberg, 1996; Schacter, Curran, Galluccio, Milberg, \& Bates, 1996) and in neuroimaging studies (Duzel, Yonelinas, Mangun, Heinze, \& Tulving, 1997; Johnson et al.,

relative to normal controls, can be demonstrated by creating conditions that are more or less conducive to allowing true recognition to suppress false recognition. With repeated presentation and testing of lists of semantic associates, control subjects and both Korsakoff and non-Korsakoff amnesics showed increasing levels of true recognition across trials. However, control subjects exhibited decreasing levels of false recognition across trials, whereas Korsakoff amnesic patients showed increases across trials and non-Korsakoff amnesics showed a fluctuating pattern. Consideration of signal detection analyses and differences between the two types of amnesic patients provides insight into how mechanisms of veridical episodic memory can be used to suppress false recognition.

1997; Schacter, Buckner, Koutstaal, Dale, \& Rosen, 1997; Schacter, Reiman, et al., 1996; for review, see Schacter, Norman, \& Koutstaal, 1998).

One of the most extensively studied types of memory distortions is known as false recognition. False recognition occurs when people claim incorrectly to have previously encountered a novel word, object, face, or event that is in some way related to a studied item (Underwood, 1965). Recent experiments using a paradigm initially developed by Deese (1959), and revived and modified by Roediger and McDermott (1995; see also Read, 1996), have demonstrated exceptionally high levels of false recognition. After studying lists of semantic associates that all converge on a nonpresented "theme word," participants frequently claim to remember the nonpresented word (cf. Israel \& Schacter, 1997; Mather, Henkel, \& Johnson, 1997; Norman \& Schacter, 1997; Payne, Elie, Blackwell, \& Neuschatz, 1996; Robinson \& Roediger, 1997; Roediger \& McDermott, 1995). 
To gain insight into the brain mechanisms underlying this memory illusion, we have recently examined false recognition in amnesic patients (Schacter, Verfaellie, \& Pradere, 1996; Schacter, Verfaellie, \& Anes, 1997). Amnesic patients exhibit severe difficulties remembering recent experiences as a consequence of damage to the medial regions of the temporal lobes and related structures in the diencephalon, yet retain normal perceptual and linguistic functions along with IQ scores within the normal range (Parkin \& Leng, 1993; Squire, 1994). Schacter, Curran, et al. (1996) exposed amnesics and matched controls to lists of semantic associates (e.g., candy, sour, sugar, bitter, good, taste, tooth, and so forth) and tested them with previously studied words (e.g., taste), new words that are semantically related to previously presented words (e.g., sweet ), and new words that are unrelated to previously studied ones (e.g., point). As expected, amnesic patients attained fewer hits to previously presented words and made more false alarms to new unrelated words than did matched controls. But amnesic patients also made significantly fewer false alarms to the nonpresented theme words than did controls, who showed high levels of false recognition to these words. In follow-up studies, we replicated this finding of reduced false recognition for semantically related words in amnesic patients and extended it to perceptual false recognition, where new words are physically, rather than conceptually, related to previously studied words (Schacter, Verfaellie, et al., 1997).

The foregoing findings suggest that the medial tempo$\mathrm{ral} /$ diencephalic structures that are damaged in amnesic patients play a role in storing and/or retrieving the semantic (or perceptual) information that drives false recognition in healthy controls. However, as noted by Schacter, Verfaellie, et al. (1996) and Schacter, Verfaellie, et al. (1997), our findings contrast with an older study of false recognition in amnesic patients reported by Cermak, Butters, and Gerrein (1973). In their experiment, new words were preceded by a single homophone, associate, or synonym. A continuous recognition procedure was used in which new and old words were intermixed and subjects responded "old" or "new" to each test item (there was no separate study list prior to the recognition test as there was in our experiments and in the other reviewed studies). In contrast to the results of our experiments, however, amnesic patients showed a higher overall level of false recognition than did controls (this result was attributable to false recognition of homophones and associates; for reasons that are unclear, neither amnesics nor controls in this experiment showed significant false recognition to synonyms).

To account for the sharp contrast between the Cermak et al. (1973) results and those of Schacter, Verfaellie, et al. (1996) and Schacter, Verfaellie, et al. (1997), we suggested that when numerous associates are presented during study (as in the Deese/Roediger-McDermott paradigm), normal controls establish a well-organized repre- sentation of the semantic or perceptual gist (Reyna \& Brainerd, 1995) of the study list; when this representation is matched by a new theme word, normal controls experience a strong sense of familiarity or recollection that produces a robust false recognition effect. Amnesic patients, by contrast, encode or retain less gist information and hence show reduced levels of false recognition. However, when only a single related item precedes a new word, as in Cermak et al.'s study, controls establish a less robust gist representation than when numerous associates are studied, and they can use their intact explicit memory abilities to suppress or oppose (Jacoby, 1991) the sense of familiarity or recollection they may experience when encountering a related new word. Thus, for example, a nonamnesic individual who encounters the nonstudied word table and can recollect having previously studied the associate chair and can use this information to avoid making a false recognition response (Brainerd, Reyna, \& Kneer, 1995). Amnesic patients, however, might be less able to use recollection to oppose or suppress whatever weak sense of familiarity or recollection is engendered by a new theme word and, therefore, exhibit increased levels of false recognition compared to nonamnesic controls.

According to this analysis, it should be possible to show, within a single experiment, greater or lesser false recognition in amnesic patients relative to normal controls by creating conditions that are more or less conducive to using explicit recollection to suppress false recognition. Note, however, that the Cermak et al. (1973) paper included only alcoholic Korsakoff amnesic patients. More recent research has shown that Korsakoff patients are characterized by cognitive deficits that are not observed in non-Korsakoff amnesics and that are likely related to frontal lobe damage (cf. Moscovitch, 1982; Schacter, 1987; Shimamura, 1995; Squire, 1982). Thus, it is possible that impairments in the ability to suppress false recognition may be present only in Korsakoff patients or that such impairments may be exacerbated in these patients. In our previous studies of false recognition (Schacter, Verfaellie, et al., 1996; Schacter, Verfaellie, et al., 1997), Korsakoff and non-Korsakoff amnesics (i.e., anoxic and encephalitic patients with medial temporal lobe damage) have performed similarly, with both subgroups of amnesic patients exhibiting impaired true recognition and reduced false recognition of related lures compared to appropriate control subjects. However, it is entirely conceivable that the contrasting pattern found in the Cermak et al. (1973) study-increased false recognition in amnesics compared to controlscould be attributable to cognitive deficits that are unique to Korsakoff patients.

In the present experiment, we tested these ideas by repeatedly presenting amnesic patients and matched controls with the same study lists of semantic associates and repeatedly testing them with lists comprised of previously studied words, semantically related lures, and 
unrelated lures. More specifically, all subjects studied six lists of words, were given a recognition test, studied the same six lists again, were given a second recognition test, and continued this sequence for a total of five study-test trials. We suggest that with repeated study and testing of the same lists, (1) normal controls would show increasing explicit recollection of previously presented words, and (2) they would use this episodic memory to reduce false alarms to related words that were not presented. Consistent with these suggestions, in a study of false recall by McDermott (1996), participants studied and recalled the same lists of semantic associates across five study-test trials. Free recall of studied words increased systematically across trials, whereas false recall (i.e., intrusions) of semantically related lures decreased systematically across trials.

We hypothesize that healthy controls will show a similar pattern on a recognition test, with true recognition of previously studied words increasing, and false recognition of semantic associates decreasing, across study-test trials. By contrast, we hypothesize a different pattern of results in amnesic patients. Based on our previous results (Schacter, Verfaellie, et al., 1996; Schacter, Verfaellie, et al., 1997), we expect that both Korsakoff and non-Korsakoff amnesic patients will show reduced levels of both true and false recognition compared to controls on the first study-test trial. We also expect that with repetition of study-test lists, both Korsakoff and non-Korsakoff amnesic patients will continue to show impaired levels of veridical recognition memory compared to controls, although (like controls) they should show some increases in true recognition across trials. Most important, in contrast to the control group, we hypothesize that both Korsakoff and non-Korsakoff amnesic patients' impoverished veridical recollections will prevent them from using episodic memory to reduce false recognition across trials. That is, even though we expect that amnesic patients will show increases in true recognition across trials, we hypothesize that these increases will not be sufficient to allow amnesic patients to suppress false recognition to the same degree as control subjects do. Our reasoning here is based on our previous suggestion that both true and false recognition performance of amnesic patients in the Deese/RoedigerMcDermott paradigm is based largely on a degraded representation of the semantic gist of the study list (Brainerd et al., 1995), with little or no contribution from specific recollections of particular studied items. As noted earlier, we assume that suppression of false recognition is facilitated by specific recollections of the prior occurrence of studied items. If repetition of studied items serves mainly to strengthen a semantic gist representation in amnesic patients, but also strengthens specific recollections of particular studied items in controls, amnesic patients will be less able to use increasing true recognition to suppress false recognition.

The aforementioned differences between Korsakoff and non-Korsakoff amnesic patients are also important to consider here. It is possible that suppression of false recognition requires the intact functioning of verification and control mechanisms, dependent on frontal lobe structures (cf. Schacter, Curran, et al., 1996; Shallice, 1988; Shimamura, 1995), which may be impaired in Korsakoff but not non-Korsakoff amnesics. Such cognitive impairments, together with impaired episodic recollection, may have contributed to the previously mentioned finding from Cermak et al. (1973) that Korsakoff patients showed higher levels of false recognition than did controls. If so, the expected finding of reduced false recognition on the first study-test trial in Korsakoff patients compared to controls should be reversed across trials, with Korsakoff patients eventually showing more false recognition than their controls. It is less clear whether such a crossover will be observed in non-Korsakoff patients, where any difficulties suppressing false recognition are likely attributable solely to deficits in episodic recollection.

\section{RESULTS}

Figure 1 displays the proportions of "old" responses to (1) previously studied words, (2) related lures that are semantic associates of previously studied words, and (3) unrelated lures that are not associates of previously studied words. These results are shown separately for each of the amnesic subgroups and their respective controls. Preliminary analyses revealed no significant differences between the two amnesic subgroups for true recognition, so we present statistical analyses of these data collapsed across the two amnesic subgroups. There were, however, some significant differences between the two subgroups for false recognition, so we analyze these data separately for Korsakoff amnesics and mixed amnesics. Following these analyses of overall recognition performance, we present signal detection analyses that provide estimates of sensitivity $\left(A^{\prime}\right)$ and bias $\left(B_{D}{ }^{\prime \prime}\right)$ for several key comparisons (Table 1).

\section{True Recognition}

Consider first analyses of the initial test trial. Compared to the control group, amnesic patients made significantly fewer old responses to studied words (0.64 versus 0.84 ; $t(22)=3.00, p<0.01)$ and significantly more old responses to unrelated lures $(0.26$ vs. $0.05 ; t(22)=4.07$, $p<0.001)$. Analyses of corrected recognition scores that were obtained by subtracting the proportion of old responses to unrelated lures from the proportion of old responses to studied words reveal that amnesic patients exhibit significantly reduced levels of recognition accuracy, $(0.38$ versus $0.79 ; t(22)=5.44, p<0.001)$.

Consideration of all five test trials indicates that true recognition was affected similarly by study-test repetitions in amnesics and controls. Repetition of study-test 


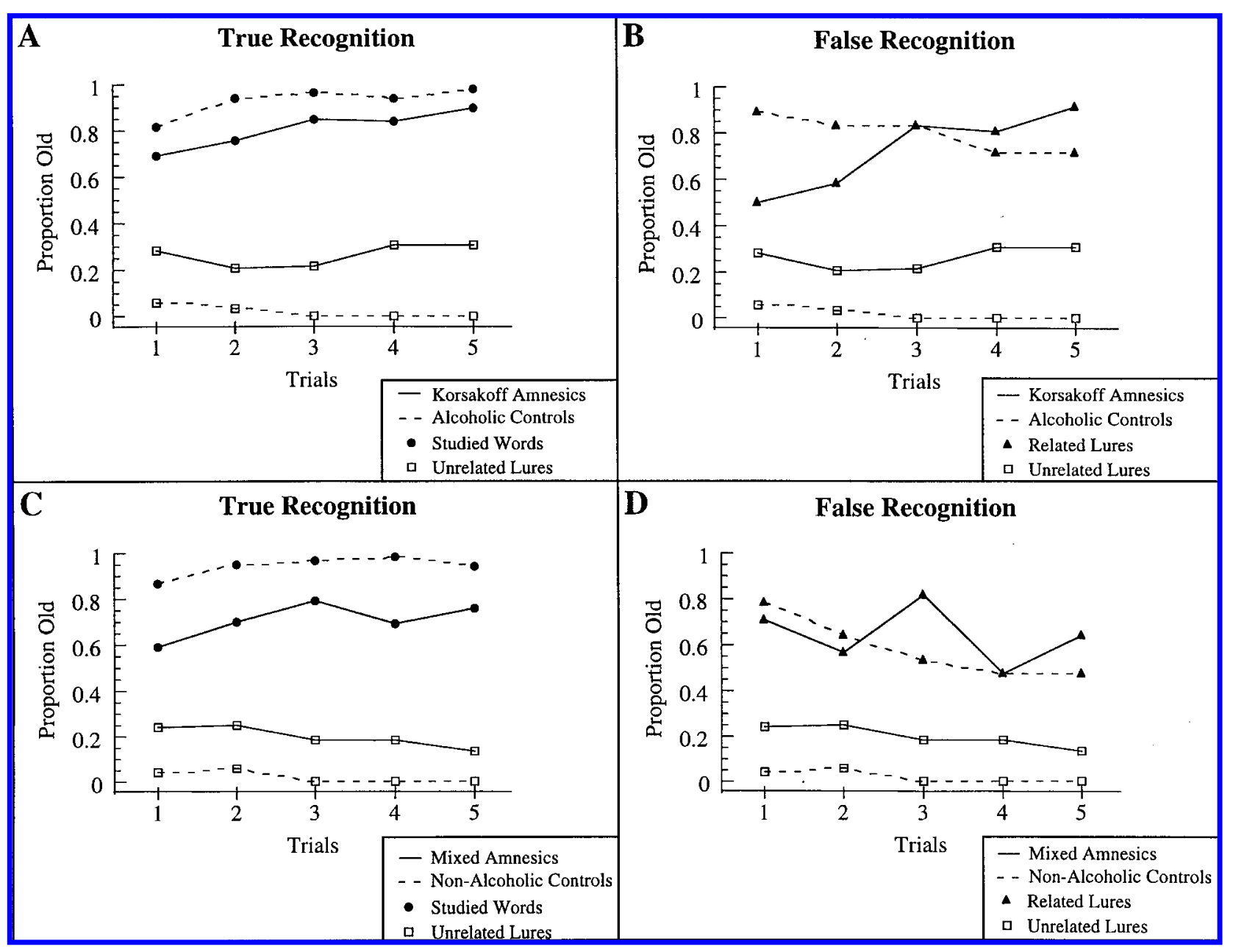

Figure 1. Proportions of old responses to studied words (Panels A and C), related lures (Panels B and D), and unrelated lures (Panels A-D) in the two subgroups of amnesics (Korsakoff and mixed) and their respective control groups (alcoholic and nonalcoholic) as a function of studytest trial. Korsakoff and mixed amnesics showed similarly impaired true recognition. However, Korsakoff patients showed increasing false recognition across trials, whereas mixed amnesics showed a fluctuating pattern across trials.

trials produced a consistent increase in the proportion of old responses to studied words made by both amnesics and controls. An analysis of variance (ANOVA) on these responses that included Group as a betweensubjects variable and Trials as a within-subjects variable shows highly significant effects of Group, $F(1,22)=$ 17.92, MSE $=0.054, p<0.001$ and Trials, $F(4,88)=10.66$, $M S E=0.009, p<0.0001$, together with a nonsignificant Group $\times$ Trials interaction $(F<1)$. The proportion of old responses to unrelated lures did not change significantly across trials in either group (note, however, that floor effects were operative for controls): an ANOVA yielded a significant effect of Group $F(1,22)=16.88, M S E=$ $0.079, p<0.001$, together with nonsignificant effects of Trials, $F(4,88)=1.03, M S E=0.010$, and Group $\times$ Trials, $F$ s $<1$. Analyses of corrected recognition scores show main effects of Group, $F(1,22)=44.65, M S E=0.103$, $p<0.0001$, and Trials $F(4,88)=12.76, M S E=0.013, p<$
0.0001 , and a nonsignificant effect of Group $\times$ Trials, $F<1$.

\section{False Recognition}

Combined across the two patient subgroups, amnesic patients made significantly fewer old responses to related lures than did controls $(0.60$ vs. $0.83 ; t(22)=2.54$, $p<0.05$ ), and showed significantly reduced levels of corrected false recognition $(0.34$ vs. $0.78 ; t(22)=4.78$, $p<0.001$ ). Separate analyses of the two patient subgroups indicate that Korsakoff amnesic patients made significantly fewer old responses to related lures than did alcoholic controls $(0.50$ vs. $89 ; t(22)=2.91, p<0.01)$. Compared to their controls, Korsakoff patients also showed a significantly lower level of corrected false recognition $(0.22$ vs. $0.83 ; t(22)=5.31, p<0.001)$, which was obtained by subtracting false alarms to unrelated 
Table 1. Signal Detection Analyses of Sensitivity $\left(A^{\prime}\right.$ and Bias $\left(B_{D}{ }^{\prime \prime}\right)$ as a Function of Study-Test Trials in Korsakoff Amnesics, Alcoholic Controls, Mixed Amnesics, and Nonalcoholic Controls

\begin{tabular}{|c|c|c|c|c|c|c|c|c|}
\hline \multirow[b]{2}{*}{ Trials } & \multicolumn{2}{|c|}{ Korsakoff amnesics } & \multicolumn{2}{|c|}{ Alcobolic controls } & \multicolumn{2}{|c|}{ Mixed amnesics } & \multicolumn{2}{|c|}{$\begin{array}{c}\text { Nonalcobolic } \\
\text { controls }\end{array}$} \\
\hline & $A^{\prime}$ & $B_{D}^{\prime \prime}$ & $A^{\prime}$ & $B_{D}^{\prime \prime}$ & $A^{\prime}$ & $B_{D}^{\prime \prime}$ & $A^{\prime}$ & $B_{D}^{\prime \prime}$ \\
\hline \multicolumn{9}{|c|}{ Item-Specific Memory (Hits Compared to Novel False Alarms) } \\
\hline 1 & 0.77 & 0.07 & 0.91 & 0.39 & 0.73 & 0.20 & 0.93 & 0.44 \\
\hline 2 & 0.84 & 0.19 & 0.95 & 0.27 & 0.77 & 0.03 & 0.95 & 0.09 \\
\hline 3 & 0.86 & -0.02 & 0.97 & 0.32 & 0.86 & 0.13 & 0.97 & 0.32 \\
\hline 4 & 0.83 & -0.13 & 0.96 & 0.41 & 0.83 & 0.27 & 0.97 & 0.32 \\
\hline 5 & 0.82 & -0.24 & 0.97 & 0.32 & 0.86 & 0.32 & 0.96 & 0.46 \\
\hline \multicolumn{9}{|c|}{ Item-Specific Memory (Hits Compared to Related False Alarms) } \\
\hline 1 & 0.65 & -0.29 & 0.46 & -0.73 & 0.42 & -0.38 & 0.57 & -0.68 \\
\hline 2 & 0.61 & -0.31 & 0.57 & -0.77 & 0.65 & -0.37 & 0.74 & -0.81 \\
\hline 3 & 0.50 & -0.67 & 0.66 & -0.95 & 0.50 & -0.56 & 0.81 & -0.80 \\
\hline 4 & 0.54 & -0.72 & 0.66 & -0.78 & 0.64 & -0.07 & 0.81 & -0.80 \\
\hline 5 & 0.47 & -0.76 & 0.69 & -0.89 & 0.59 & -0.48 & 0.78 & -0.63 \\
\hline \multicolumn{9}{|c|}{ Gist Memory (Related False Alarms Compared to Novel False Alarms) } \\
\hline 1 & 0.66 & 0.10 & 0.93 & 0.36 & 0.78 & 0.14 & 0.90 & 0.58 \\
\hline 2 & 0.76 & 0.31 & 0.92 & 0.45 & 0.70 & 0.33 & 0.86 & 0.55 \\
\hline 3 & 0.86 & -0.08 & 0.93 & 0.63 & 0.86 & 0.12 & 0.85 & 0.87 \\
\hline 4 & 0.81 & -0.11 & 0.90 & 0.74 & 0.72 & 0.24 & 0.84 & 0.84 \\
\hline 5 & 0.85 & -0.26 & 0.90 & 0.67 & 0.83 & 0.40 & 0.84 & 0.84 \\
\hline
\end{tabular}

lures from false alarms to related lures. Mixed amnesics made numerically fewer old responses to related lures than did their controls ( 0.69 vs. 0.78$)$, but the difference was not significant, $t<1$. However, mixed amnesics did show significantly lower levels of corrected false recognition than did their controls, $(0.46$ vs. $0.83 ; t(22)=2.06$, $p<0.05)$. Thus, the overall pattern of first trial data is generally consistent with our previous findings of reduced false recognition in both amnesic subgroups (Schacter, Verfaellie, et al., 1996; Schacter, Verfaellie, et al., 1997).

Consideration of all five test trials (Figure 1) indicates that Korsakoff patients showed steadily increasing levels of false recognition across trials, resulting in a crossover interaction with the alcoholic control group: Korsakoff patients showed lower levels of false recognition than alcoholic controls on the first trial and higher levels of false recognition on the final trial. Mixed amnesics showed fluctuating levels of false recognition across trials, contrasting with consistent decreases shown by nonalcoholic controls, also producing a crossover between the first and final trials.
ANOVAs on overall false recognition responses and corrected false recognition responses that compared Korsakoff patients to alcoholic controls each showed significant Group $\times$ Trials interactions, $F \mathrm{~s}(1,40)>3.65$, ps $<0.02$. Comparisons between mixed amnesics and their controls also reveal Group $\times$ Trials interactions for overall false recognition and corrected false recognition, $F s(1,40)>2.87, p s<0.05$. Direct comparisons between mixed amnesics and Korsakoff patients also show a significant Group $\times$ Trials interaction for overall false recognition, $F(1,40)=4.31, p<0.01$, and a trend toward such an interaction for corrected false recognition, $F(1,40)=$ $2.12, p=0.096$.

To explore further the nature of changes in false recognition across trials, we conducted linear trend analyses on overall false recognition scores and corrected false recognition scores (Rosenthal \& Rosnow, 1985). An ANOVA comparing Korsakoff patients and alcoholic controls showed significant Groups $\times$ Trials interactions for both overall and corrected false recognition, $F s(1,40)>$ 13.26, $p<0.001$, indicating that the slopes of the two groups differed. The Korsakoff patients showed a sig- 
nificant linear increase across trials for both overall and corrected false recognition, $F \mathrm{~s}(1,20)>12.19, p<0.005$, whereas alcoholic controls showed a significant linear decrease for overall false recognition, $F(1,20)=4.39$, $p<0.05$, and a nonsignificant trend for a decrease in corrected false recognition, $F(1,20)=1.75$. An ANOVA comparing mixed amnesics and healthy controls showed significant Group $\times$ Trials interactions for both overall and corrected false recognition, $F \mathrm{~s}(1,40)>4.58, p<$ 0.05 , confirming that the slopes of mixed amnesics and their controls differed. Healthy controls showed a significant linear decrease in both analyses, $F \mathrm{~s}(1,20)>$ $11.64, p s<0.005$, whereas mixed amnesic showed no evidence of a linear trend, $F \mathrm{~s}<1$.

\section{Signal Detection Analyses}

To determine whether the main findings of the experiment are attributable to changes in sensitivity or response bias, we performed signal detection analyses that have been described and applied to similar kinds of true versus false recognition data by Koutstaal and Schacter (1997) and Tussing and Greene (1998), using $A^{\prime}$ as an estimate of sensitivity and $\mathrm{B}_{\mathrm{D}}$ " as an estimate of response bias (Donaldson, 1993; Snodgrass \& Corwin, 1988). Values of $\mathrm{A}^{\prime}$ can vary between 0 and 1.00; higher values indicate greater sensitivity, with 0.50 indicating chance performance. Values of the bias measure, $\mathrm{B}_{\mathrm{D}}{ }^{\prime \prime}$, can vary between -1.00 (indicating extremely liberal responding) and +1.00 (indicating extremely conservative responding). Because these measures are undefined with hit rates of 0 or 1, the data were first transformed, as recommended by Snodgrass and Corwin, by computing $p(x)$ as $(x+0.5) / n+1$ rather than $x / n$. In addition, when individual subjects showed below chance sensitivity (hits < false alarms, or $\mathrm{A}^{\prime}<0.50$ ), modified formulas provided by Aaronsen and Watts (1987) were used.

Following Koutstaal and Schacter (1997), we provide three different types of signal detection analyses, shown in the upper, middle, and lower panels of Table 1 . The uppermost panel of Table 1 shows estimates of sensitivity and bias comparing hits (i.e., old responses to studied items) with false alarms to unrelated lures, which constitutes a measure of item-specific true recognition (referred to as $\mathrm{A}^{\prime}$ unrelated and $\mathrm{B}_{\mathrm{D}}{ }^{\prime \prime}$ unrelated for sensitivity and bias, respectively). The middle panel compares hits with false alarms to related lures, which provides a different measure of item-specific true recognition $\left(\mathrm{A}^{\prime}\right.$ related and $\mathrm{B}_{\mathrm{D}}{ }^{\prime \prime}$ related for sensitivity and bias, respectively). In the bottom panel of Table 1 , false alarms to related lures are depicted as a form of memory for the "gist" of the study list (cf. Brainerd et al., 1995; Koutstaal \& Schacter, 1997) and thus are treated in the same manner as hits in the previous two analyses. For this analysis, false alarms to related lures are compared to false alarms to unrelated lures; $\mathrm{A}^{\prime}$ indicates the extent to which subjects called related lures old compared to how often they called unrelated lures old. We call these measures of sensitivity and bias $\mathrm{A}^{\prime}$ gist and $\mathrm{B}_{\mathrm{D}}$ " gist, respectively.

\section{Item-Specific Memory (Hits Compared to Unrelated Lure False Alarms)}

Table 1 shows that, not surprisingly, $\mathrm{A}^{\prime}$ unrelated was consistently higher in both groups of controls than in Korsakoff and mixed amnesics, reflecting a greater ability for controls than amnesics to distinguish between studied words and unrelated lures. $\mathrm{A}^{\prime}$ unrelated increased across trials for all groups, reaching near-ceiling levels for controls. Because there were no significant subgroup differences for this analysis, an ANOVA was performed on data from the entire group of amnesics and controls. This analysis revealed significant main effects for Group, $F(1,22)=28.29, M S E=0.020, p<0.0001$, and Trials, $F(4$, $88)=6.54, M S E=0.004, p<0.0001$, along with a nonsignificant effect of Group $\times$ Trials, $F<1$. The bias measure, $\mathrm{B}_{\mathrm{D}}{ }^{\prime \prime}$ unrelated, indicates moderately conservative responding on the part of both groups. An ANOVA failed to reveal significant effects of Group or Trials, although there was a slight trend for more conservative responding on the part of controls (for Group, $F(1,22)=$ $2.45, M S E=0.763, p=0.132 ;$ other $F \mathrm{~s}<1)$.

\section{Item-Specific Memory (Hits Compared to Related Lure False Alarms)}

The $\mathrm{A}^{\prime}$ related values in the middle panel of Table 1 reflect the extent to which participants distinguish between studied words and related lures. Perhaps the most notable feature of these data is that nonalcoholic controls, alcoholic controls, and mixed amnesics all show trends for increasing $\mathrm{A}^{\prime}$ related across trials, whereas Korsakoff patients show the opposite effect. An ANOVA comparing Korsakoff patients and alcoholic controls revealed a significant Group $\times$ Trials interaction, $F(4,40)=$ 3.94, $p<0.01$. A comparison between mixed amnesics and nonalcoholic controls documented significant effects of Group, $F(1,10)=10.76, p<0.01$, indicating that mixed amnesics had greater difficulty distinguishing between studied words and related lures than did controls across all trials; there was also a significant effect of Trials, $F(4,40)=6.13, p<0.001$, and a nonsignificant effect of Group $\times$ Trials, $F<1$.

The values of $\mathrm{B}_{\mathrm{D}}$ " related in the middle panel of Table 1 indicate that when old responses to related lures are treated as false alarms, all groups respond quite liberally, with each group of controls tending to respond more liberally than either group of amnesic patients, $F \mathrm{~s}(1$, 10) $<4.01, p<0.08$. Korsakoff patients showed a marginally significant tendency to respond more liberally across trials, $F(4,20)=2.75, p=0.057$, whereas each of the other groups showed fluctuating patterns. 
Gist Memory (Related Lure False Alarms Compared to Unrelated Lure False Alarms)

$A^{\prime}$ gist, shown in the lower panel of Table 1, does not necessarily indicate the amount of gist memory available to subjects but rather reflects their tendency to rely on gist despite any opposing influence of item-specific memory. As can be seen in Table 1, the most marked effects for $\mathrm{A}^{\prime}$ gist are seen in the Korsakoff patients. Levels of $A^{\prime}$ gist were generally lower in Korsakoff patients than in alcoholic controls. But in the Korsakoff patients, $\mathrm{A}^{\prime}$ gist increased substantially across trials, $F(4$, 20) $=5.96, p<0.01$, whereas $\mathrm{A}^{\prime}$ gist showed slight but nonsignificant decreases across trials in alcoholic controls, $F<1$. An ANOVA comparing the two groups revealed significant main effects of Group, $F(1,10)=10.11$, $p<0.01$, and Trials, $F(4,40)=4.06, p<0.01$, and most important, a significant Group $\times$ Trials interaction, $F(4$, 40) $=5.02, p<0.01$.

In mixed amnesic patients, $\mathrm{A}^{\prime}$ gist showed a fluctuating pattern, with nonsignificant changes across trials, $F(4$, $20)=2.14$, whereas nonalcoholic controls showed a nonsignificant trend for decreasing $\mathrm{A}^{\prime}$ gist across trials, $F(4,20)=1.86$. Mixed amnesics showed somewhat lower levels of $\mathrm{A}^{\prime}$ gist than did nonalcoholic controls on the early trials that were not evident on the final trial; a combined ANOVA revealed trends toward effects of Group, $F(1,10)=3.49, p=0.091$, Trial, $F(4,40)=2.12$, $p=0.096$, and Group $\times$ Trial, $F(4,40)=2.09, p=0.10$.

$\mathrm{B}_{\mathrm{D}}{ }^{\prime \prime}$ in this analysis was generally lower in Korsakoff patients than in alcoholic controls, $F(1,10)=4.71, p=$ 0.055 , indicating more liberal responding on the basis of gist in the Korsakoff group. There was also a significant Group $\times$ Trials interaction, $F(4,40)=2.89, p<0.05$, which reflects nonsignificant trends for decreasing $B_{\mathrm{D}}$ " across trials in Korsakoff patients, $F(4,20)=1.57$, together with trends for increases across trials in alcoholic controls, $F(4,20)=1.94$. $\mathrm{B}_{\mathrm{D}}{ }^{\prime \prime}$ was also somewhat lower in mixed amnesics than in nonalcoholic controls, $F(1$, $10)=3.47, p=0.09$. $\mathrm{B}_{\mathrm{D}}$ " increased significantly across trials in nonalcoholic controls, $F(4,20)=3.16, p<0.05$, indicating increasingly conservative responding, whereas $\mathrm{B}_{\mathrm{D}}{ }^{\prime \prime}$ did not change across trials in mixed amnesics, $F<$ 1. However, the Group $\times$ Trial interaction was not significant, $F(4,40)=1.63$.

\section{GENERAL DISCUSSION}

In previous research, we (Schacter, Verfaellie, et al., 1996; Schacter, Verfaellie, et al., 1997) found that amnesic patients show reduced false recognition of semantic associates in a paradigm that yields high levels of false recognition in healthy controls. The present experiment has extended this work and related it to earlier research showing increased false recognition in Korsakoff amnesics (Cermak et al., 1973) by demonstrating different patterns of false recognition suppression in both Korsa- koff and non-Korsakoff amnesic patients compared to matched controls. Analysis of results from the first trial confirmed results of Schacter, Verfaellie, et al. In addition to showing impaired levels of true recognition for studied words, both subgroups of amnesic patients showed substantially reduced levels of corrected false recognition compared to controls.

Across trials, true recognition of studied words increased in all groups, whereas false recognition of related lures decreased significantly in the nonalcoholic controls and showed similar trends in alcoholic controls. In contrast, mixed amnesic patients showed fluctuating levels of false recognition across trials, whereas Korsakoff patients showed clear and consistent evidence for increasing levels of false recognition across trials. Signal detection analyses indicated that across trials, control subjects showed relatively constant levels of sensitivity to gist and used increasingly conservative response criteria to related versus unrelated lures; changes in response criteria were most evident in nonalcoholic controls. Korsakoff patients, by contrast, used relatively constant response criteria for related versus unrelated lures across trials but showed increasing sensitivity to gist influences, whereas mixed amnesic patients failed to show significant changes in either sensitivity to gist or in the response critiera used to respond to related versus unrelated lures.

The increasing sensitivity to gist influences seen in Korsakoff patients indicates that repeated study and testing of semantic associates creates an increasingly robust representation of semantic gist that, when entirely unchecked by veridical memory, produces increasingly elevated levels of false recognition. Repeated study and testing also presumably lead to an increasingly robust gist representation in control subjects, but they can make use of explicit recollection to employ increasingly conservative response criteria that serve to counteract or suppress the strengthening gist representation. These observations are consistent with our earlier suggestion that the contrasting results obtained in previous studies-Korsakoff amnesics showing increased false recognition in the continous recognition experiments of Cermak et al. (1973), where related lures are preceded by only a single associate, and decreased false recognition in our recent experiments (Schacter, Verfaellie, et al., 1996; Schacter, Verfaellie, et al., 1996), where related lures are preceded by numerous associates-reflect the differential operation in these two paradigms of mechanisms for suppressing false recognition.

Although the mixed amnesic group did not show reliable reductions of false recognition across trials, the fact that false recognition did not increase significantly across trials in these patients suggests that mixed amnesics were at least partially able to suppress the strengthening gist influence. The observed difference in suppression of false recognition between the two amnesic subgroups is unlikely to be related to severity of 
amnesia: mean delay scores on WMS-R in the Korsakoff amnesics $(m=57.3)$ are similar to those in the mixed amnesics ( $m=58.8$; see Table 2 ). Morever, in the present experiment the true recognition scores of Korsakoff patients were actually somewhat higher than those of mixed amnesics on the first trial (corrected recognition scores were 0.50 and 0.39 for Korsakoff patients and mixed amnesics, respectively). Note also, however, that by the fifth trial, corrected true recognition scores of mixed amnesic patients (0.67) were higher than those of Korsakoff patients (0.59). These findings suggest that the veridical recognition of Korsakoff patients failed to benefit from study-test trials to the same extent as the veridical recognition of the mixed amnesics.

Because the first trial data undermine any simple interpretation in terms of severity of amnesia, it is likely that previously mentioned cognitive deficits that are unique to Korsakoff patients, and that may be related to frontal lobe damage (cf. Moscovitch, 1982; Schacter, 1987; Shimamura, 1995; Squire, 1982), contribute to Korsakoff patients' severely impaired ability to suppress the strengthening across-trial influence of semantic gist. Consistent with this possibility, damage to the frontal lobes has been linked recently with high levels of false recognition (Parkin et al., 1996; Schacter, Verfaellie, et al., 1996). Moreover, a number of neuroimaging studies have strongly implicated various regions within the frontal lobes in episodic memory (cf., Buckner, Petersen, Ojemann, Miezin, Squire, \& Raichle, 1995; Nyberg et al., 1995; Schacter, Alpert, Savage, Rauch, \& Albert, 1996; Shallice, Fletcher, Frith, Grasby, Frackowiak, \& Dolan, 1994; Tulving, Kapur, Craik, Moscovitch, \& Houle, 1994). Recent evidence suggests that activity within anterior prefrontal regions may be specifically related to postretrieval monitoring and verification processes (Rugg, Fletcher, Frith, Frackowiack, \& Dolan, 1996; Schacter, Buckner, et al., 1997; Schacter, Reiman, et al., 1996; Wilding \& Rugg, 1996). Such processes, which may be related to the inhibitory functions of the frontal lobes (Shimamura, 1995), would presumably be required to use episodic information to suppress false recognition and are likely impaired in Korsakoff patients.

An alternative possibility is that deficits in source memory, commonly seen in patients with frontal lobe damage (Janowsky, Shimamura, \& Squire, 1989; Schacter, Harbluk, \& McLachlan, 1984), are implicated in the effects we observed. Because items were repeatedly presented and tested across trials, the ability to discriminate studied items from related lures required consideration of their source: On later trials, both studied items and related lures had been previously encountered, but related lures-in contrast to studied items-were presented only on earlier test lists (and not on earlier study lists). Perhaps Korsakoff patients had particular difficulty

Table 2. Characteristics of Korsakoff and Mixed Amnesics Patients

\begin{tabular}{|c|c|c|c|c|c|c|c|}
\hline \multirow[b]{2}{*}{ Patient } & \multirow[b]{2}{*}{ Etiology } & \multirow[b]{2}{*}{ Age } & \multirow[b]{2}{*}{$E D$} & \multirow[b]{2}{*}{$V I Q$} & \multicolumn{3}{|c|}{ WMS-R } \\
\hline & & & & & $G M$ & $D L Y$ & $A T N$ \\
\hline R.D. & Korsakoff & 67 & 12 & 83 & 66 & 50 & 99 \\
\hline W.R. & Korsakoff & 69 & 7 & 88 & 76 & 53 & 96 \\
\hline R.M. & Korsakoff & 77 & 14 & 112 & 91 & 68 & 95 \\
\hline L.B. & Korsakoff & 63 & 11 & 90 & 99 & 61 & 99 \\
\hline A.A. & Korsakoff & 70 & 9 & 93 & 76 & 62 & 109 \\
\hline C.G. & Korsakoff & 59 & 12 & 89 & 62 & 50 & 91 \\
\hline Mean & & 67.5 & 10.8 & 92.5 & 78.3 & 57.3 & 98.2 \\
\hline P.S. & anoxia & 39 & 14 & 95 & 90 & 50 & 115 \\
\hline D.F. & encephalitis & 47 & 16 & 111 & 81 & 69 & 107 \\
\hline J.M. & anoxia & 47 & 12 & 89 & 70 & 52 & 95 \\
\hline P.D. & anoxia & 60 & 20 & 109 & 65 & 61 & 89 \\
\hline S.S. & encephalitis & 69 & 18 & 126 & 102 & 50 & 114 \\
\hline C.W. & anoxia & 39 & 12 & 104 & 88 & 71 & 108 \\
\hline Mean & & 50.2 & 15.3 & 105.7 & 82.7 & 58.8 & 104.7 \\
\hline
\end{tabular}

Note $:$ ED = years of formal education. VIQ = Verbal IQ from the Wechsler Adult Intelligence Scale (Revised). WMS-R = Wechsler Memory ScaleRevised; scores are presented separately for the indices of general memory (GM), delay (DLY), and attention (ATN). The WMS-R does not provide scores below 50 , and 50 was the lowest score used to compute means. 
in remembering whether an item was presented in a study or a test list (cf. Parkin, Leng, \& Hunkin, 1990, for a similar finding).

We cannot distinguish between the two foregoing possibilities definitively, but one feature of our results calls into question the idea that source memory is critically important for suppression of false recognition in our paradigm. If healthy controls used intact source memory abilities to suppress false recognition by recollecting correctly that they encountered related lures on prior tests and not on study lists, suppression of false recognition should have been expressed in our signal detection analyses primarily by changes in $\mathrm{A}^{\prime}$ gist; that is, controls should have been able to selectively reduce old responses to related lures. Although there were some trends in this direction, the data indicate that suppression was expressed mainly through the use of a more conservative criterion, perhaps reflecting intact verification processes or inhibitory functions. Future studies could examine the roles of verification/inhibition mechanisms on the one hand and study-test source confusions on the other, with a modified paradigm in which repeatedly studied sets of semantic associates and their related lure words are not tested repeatedly; estimates of firsttrial performance could be obtained on a different set of items that is not presented again for study or for test. If impaired verification/inhibition mechanisms are responsible for the effects we observed in Korsakoff patients, Korsakoff patients should show the same pattern of increasing false recognition observed here; if the effects we observed are attributable to source confusions, Korsakoff patients should not show increasing false recognition in the modified paradigm.

Although the across-trial increases in false recognition exhibited by Korsakoff patients are perhaps the most dramatic effects in our experiment, the fact that mixed amnesic patients showed significantly less suppression of false recognition than did nonalcoholic controls indicates that impaired suppression of false recognition is not produced entirely by cognitive impairments that are unique to Korsakoff patients. Rather, these data suggest that poor episodic memory also contributes to impaired suppression of false recognition: the relative inability of both mixed amnesic patients and Korsakoff patients to remember which words had been presented reduces their ability to remember which words had not been presented. Consistent with this suggestion, Israel and Schacter (1997) found that college students who studied semantic associates that were each paired with a distinctive picture, which increased the accuracy of veridical recognition, later showed significantly fewer false recognition responses than did subjects who studied semantic associates without accompanying pictures.

If normal controls used their increasing veridical episodic memory to reduce false recognition, why did increasing across-trial memory for studied words produce different effects on false recognition in amnesic patients?
As noted earlier, both subgroups of amnesic patients showed increases in true recognition across trials that were comparable to those observed in the two control groups. Consider first the Korsakoff patients. To the extent that failure of suppression is produced in part by impairments that are distinct from poor veridical recognition memory, it is not surprising that increasing veridical memory is not sufficient to yield suppression of false recognition: Impaired verification/control mechanisms, or poor source memory, do not allow Korsakoff patients to use veridical memories to suppress false recognition.

The foregoing considerations do not account for our finding that mixed amnesic patients failed to show significant suppression effects. We suggest that veridical recognition in mixed amnesic patients (and Korsakoff patients) is simply too impoverished to support suppression of false recognition. As noted in the "Introduction," we have argued previously that for amnesic patients, true recognition in the Deese/Roediger-McDermott paradigm is based largely or entirely on a degraded representation of the semantic gist of the study list. Relevant evidence from the present experiment comes from the finding that $A^{\prime}$ related-the ability to distinguish previously studied items from related lures-was significantly greater in both groups of controls than in each of the amnesic groups. Moreover, even though true recognition increased across trials in both groups of amnesic patients, fifth trial recognition accuracy was still considerably lower in each amnesic subgroup than first trial recognition accuracy in either control group. It is possible that with further repetition of study lists or other manipulations, episodic memory in the amnesic patients could be brought to a high enough level to produce significant suppression of false recognition. At very high levels of recognition performance, amnesic patients may have sufficiently detailed item-specific recollections (as opposed to degraded gist representations) that allow them to successfully suppress false recognition. Based on the present results, we would expect such effects to be most pronounced in mixed amnesic patients, where failures to show normal suppression are probably attributable to poor episodic memory; that is, we would predict that simply raising levels of veridical recognition in mixed amnesic patients to the level of control subjects would allow them to exhibit normal suppression of false recognition. By contrast, we would not expect to observe such a pattern with the Korsakoff patients: If both cognitive impairments and poor episodic recognition contribute to the observed patterns of increasing false recognition observed in Korsakoff patients, even with higher levels of veridical recognition, such patients may still fail to show normal suppression effects.

The present data add to a growing list of experimental situations in which the encoding of specific information that guides veridical episodic memory induces nonamnesic subjects to adopt conservative response criteria that help to suppress false recognition (see Miller \& 
Wolford, 1997, for further discussion of criterion effects and false recognition). This outcome was observed in Israel and Schacter's (1997) study of pictorial encoding, where encoding distinctive pictures was associated with the adoption of conservative response criteria and reduced false recognition. Curran, Schacter, Norman, and Galluccio (1997) reported something similar in a patient with a right frontal lobe lesion, BG, who exhibits exceptionally high levels of false recognition: When induced to engage in elaborative encoding of target materials, BG used more conservative response criteria and showed reduced false recognition.

After considering similar findings in the context of cognitive aging, Schacter, Koutstaal, and Norman (1997) argued that future studies of false memory processes should focus on interactions between encoding and retrieval processes. Although this is a familiar theme in the study of veridical recollections (Tulving \& Thomson, 1973), it has not yet been applied systematically to false recognition; Schacter et al. (1998) have sketched a theoretical framework that attempts to specify some of the relevant components. Our results encourage such an approach, which could be usefully applied to different patient populations in which false recognition has been observed (e.g., Metcalfe et al.,1995), new experimental paradigms for producing the phenomenon (e.g., Koutstaal \& Schacter, 1997; Miller \& Gazzaniga, in press), and neuroimaging techniques for examining the brain activity that underlies the various manifestations of false recognition (Duzel et al., 1997; Johnson et al., 1997; Schacter, Reiman, et al., 1996; Schacter, Buckner, et al., 1997). Experimental paradigms such as the one we have introduced here, along with related paradigms that place different types of memory processes in opposition (Jacoby, 1991), provide a useful means for decomposing and understanding the dynamic interplay of psychological and biological processes that contribute to both accuracy and inaccuracy in memory performance.

\section{METHOD}

\section{Subjects}

Twelve amnesic patients ( 8 males, 4 females) and 12 individuals with intact memory functioning (controls; 9 males, 3 females) participated in the experiment. The amnesic patients and controls had all been screened at the Memory Disorders Research Center of the Boston VAMC (for details concerning individual patients, see Schacter, Verfaellie, et al., 1996). Six patients had a diagnosis of alcoholic Korsakoff syndrome and six patients had nonalcoholic etiologies (anoxia and encephalitis). This combined group of amnesics had a mean age of 58.8 years and a mean of 13.1 years of education. The amnesics were matched with 12 control subjects ( 6 with a history of alcoholism and 6 without a history of alcoholism) on the basis of age (mean $=56.8$ years) and education (mean $=13.5$ years; both $t \mathrm{~s}<1$ ). The amnesic patients' mean verbal IQ score as measured by the Wechsler Adult Intelligence Scale-Revised (WAIS-R) was 99, which did not differ from that of the control subjects $($ VIQ $=105), t(22)=1.10$. The patients' mean General Memory Index as measured with the Wechsler Memory Scale-Revised (WMS-R) was 79, with an Attention Index of 101. A Delayed Memory Index of 58 in the patient group was indicative of their severe memory deficits. Details concerning individual patients, and separate means for the Korsakoff and non-Korsakoff patient subgroups, are presented in Table 2 .

\section{Materials, Design and Procedure}

Materials were selected from the lists of semantic associates published by Roediger and McDermott (1995) and supplemented by Stadler, Roediger, and McDermott (in press). For the study lists, two sets of six 15 -word lists were chosen, Set A and Set B. For each of the six 15-word lists, there was a critical nonpresented "theme word" or related lure on which all the associates converge, and that is not presented during the study phase of the experiment (e.g., for the 15-word list containing the presented words cigarette, puff, blaze, billows, pollution, ashes, cigar, and so forth, the related lure was smoke). The two word sets were matched with respect to the mean false alarm rate to the related lure word for each list, as indicated by the norms assembled by Stadler et al. (1997). Half of the participants studied only lists from Set A, and the other half of the participants studied only lists from Set B. Over the five study repetitions, list order was manipulated such that a particular list never occurred in the same position of the six possible positions. Study words within each list were presented in the same order each time, from the highest associate to the lowest.

Participants were instructed to read the study words out loud and to remember them for a test session that would follow immediately. Participants began each study session by pressing the space bar on an Apple Macintosh Powerbook 5300c computer, after which the first study list was presented, one word at a time for $3 \mathrm{sec}$ each, in the center of the screen, which was placed a comfortable viewing distance from the participant. There was a 1-sec interval between study words. The six study lists were presented successively without interruptions. Subjects were told that there would be five study-test sessions, all using the same procedure, but were not told that the study materials would be repeatedly presented and tested.

Each test list was composed of 36 words. Six of these words were related lures (the nonpresented theme words). Eighteen of the tested items were studied words, with three studied words selected from input positions 1,8 , and 10 of each list. Twelve of the tested words were unrelated lures that had not been presented at study. For 
the first test list, six of the unrelated lures were related lure words for the word set (Set A or Set B) that had not been presented to a particular subject (thus, for example, for a subject who was never exposed to the list of words including cigarette, puff, blaze, billows, pollution, asbes, cigar, and so forth, smoke constituted an unrelated lure word). The other six unrelated lures were taken from position 6 of the lists to which the subject had not been exposed (e.g., ashes). Analyses of false alarm rates to these two different types of unrelated lure words indicated no significant differences between them or interactions with subject group ( $F$ s $<2.11$ ), so the two types of unrelated lures were treated as a single category in all experimental analyses.

To obtain an estimate of the unrelated lure false alarm rate after the first test, it was necessary to use new words that had not been previously studied or tested in the experiment. Thus, for each of the subsequent four test lists we chose six related lures and six words from position 6 of Roediger and McDermott (1995) word lists that were not otherwise studied or tested in this experiment. These unrelated lures were randomly assigned to a particular test and were always tested following the same study lists. Following this procedure, all unrelated lures for each recognition test appeared only on that test; no unrelated lures were repeated.

The order of test words was randomized for each test list, with the constraints that no more than three words from a single study list appeared consecutively, that no more than three words of a particular type (studied word, related lure, unrelated lure) appeared consecutively, and so that no more than three words requiring a correct response of either Yes or No appeared consecutively. Test words were presented visually in the same font and size as at study and were shown until the participant responded. A reminder of the key assignments for the recognition response was presented at the bottom of the computer monitor for the duration of the recognition testing.

\section{Acknowledgments}

Supported by National Institute on Aging AG08441 and National Institute of Neurological Disorders and Stroke NS26985. We thank Carolyn Brenner for help with preparation of the manuscript and thank Wilma Koutstaal for helpful comments concerning an earlier draft of the paper.

Reprint requests should be sent to Daniel L. Schacter, Department of Psychology, Harvard University, 33 Kirkland St., Cambridge, MA 02138.

\section{REFERENCES}

Aaronson, D., \& Watts, B. (1987). Extensions of Grier's computational formulas for $\mathrm{A}^{\prime}$ and $\mathrm{B}^{\prime \prime}$ to below-chance performance. Psychological Bulletin, 102, 439-442.

Brainerd, C. J., Reyna, V. F., \& Kneer, R. (1995). False-recogni- tion reversal: When similarity is distinctive. Journal of Memory and Lanquage, 34, 157-185.

Buckner, R. L., Petersen, S. E., Ojemann, J. G., Miezin, F. M., Squire, L. R., \& Raichle, M. E. (1995). Functional anatomical studies of explicit and implicit memory retrieval tasks. Journal of Neuroscience, 15, 12-29.

Cermak, L. S., Butters, N., \& Gerrein, J. (1973). The extent of the verbal encoding ability of Korsakoff patients. Neuropsychologia. 11, 85-94.

Curran, T., Schacter, D. L., Norman, K. A., \& Galluccio, L. (1997). False recognition after a right frontal lobe infarction: Memory for general and specific information. Neuropsychologia. 35, 1035-1049.

Deese, J. (1959). On the prediction of occurrence of particular verbal intrusions in immediate recall. Journal of Experimental Psychology 58, 17-22.

Donaldson, W. (1993). Accuracy of $\mathrm{D}^{\prime}$ and $\mathrm{A}^{\prime}$ as estimates of sensitivity. Bulletin of the Psychonomic Society, 31, 271274.

Duzel, E., Yonelinas, A. P., Mangun, G. R., Heinze, H. J., \& Tulving, E. (1997). Event-related brain potential correlates of two states of conscious awareness in memory. Proceedings of the National Academy of Sciences, 94, 5973159738.

Israel, L., \& Schacter, D. L. (1997). Pictorial encoding reduces false recognition of semantic associates. Psychonomic Bulletin \& Review, 4, 577-581.

Jacoby, L. L. (1991). A process dissociation framework: Separating automatic from intentional uses of memory. Iournal of Memory and Language. 30, 513-541.

Janowsky, J. S., Shimamura, A. P., \& Squire, L. R. (1989). Source memory impairment in patients with frontal lobe lesions. Neuropsychologia, 27, 1043-1056.

Johnson, M. K., Hashtroudi, S., \& Lindsay, D. S. (1993). Source monitoring. Psychological Bulletin, 114, 3-28.

Johnson, M. K., Nolde, S. F., Mather, M., Kounios, J., Schacter, D. L., \& Curran, T. (1997). Test format can affect the similarity of brain activity associated with true and false recognition memory. Psychological Science, 8, 250-257.

Koutstaal, W., \& Schacter, D. L. (1997). Gist-based false recognition of pictures in older and younger adults. Iournal of Memorv and Language, 37, 555-583.

Kroll, N. E. A., Knight, R. T., Metcalfe, J., Wolf, E. S., \& Tulving, E. (1996). Cohesion failure as a source of memory illusions. Journal of Memory and Language, 35, 176-196.

Mather, M., Henkel, L. A., \& Johnson, M. K. (1997). Evaluating characteristics of false memories: Remember/know judgments and memory characteristics questionnaire compared. Memory and Cognition, 25, 826-837.

McDermott, K. B. (1996). The persistence of false memories in list recall. Journal of Memory and Language. 35, 212230.

Metcalfe, J., Funnell, M., \& Gazzaniga, M. S. (1995). Righthemisphere memory superiority: Studies of a split-brain patient. Psychological Science, 6, 157-164.

Miller, M. B., \& Gazzaniga, M. S. (in press). Creating false memories for visual scenes. Neuropsychologia.

Miller, M. B., \& Wolford, G. (1997). False memory or criterion shift. Manuscript submitted for publication.

Moscovitch, M. (1982). Multiple dissociations of function in amnesia. In L. S. Cermak (Ed.), Human memory and amnesia (pp. 337-370). Hillsdale, NJ: Erlbaum.

Moscovitch, M. (1995). Confabulation. In D. L. Schacter, J. T. Coyle, G. D. Fischbach, M.-M. Mesulam, \& L. E. Sullivan (Eds.), Memory distortion: How minds, brains, and societies reconstruct the past (pp. 226-254). Cambridge, MA: Harvard University Press.

Norman, K. A., \& Schacter, D. L. (1997). False recognition in 
young and older adults: Exploring the characteristics of illusory memories. Memory and Cognition, 25, 838-848.

Nyberg, L., Tulving, E., Habib, R., Nilsson, L.-G., Kapur, S., Houle, S., Cabeza, R., \& McIntosh, A. R. (1995). Functional brain maps of retrieval mode and recovery of episodic information. NeuroReport, 6, 249-252.

Parkin, A. J., Bindschaedler, C., Harsent, L., \& Metzler, C. (1996). Pathological false alarm rates following damage to the left frontal cortex. Brain and Cognition, 32, 14-27.

Parkin, A. J., \& Leng, N. R. C. (1993). Neuropsychology of the amnesic syndrome. Hillsdale, NJ: Erlbaum.

Parkin, A. J., Leng, N. R. C., \& Hunkin, N. M. (1990). Differential sensitivity to contextual information in diencephalic and temporal lobe amnesia. Cortex, 26, 373-380.

Payne, D. G., Elie, C. J., Blackwell, J. M., \& Neuschatz, J. S. (1996). Memory illusions: Recalling, recognizing, and recollecting events that never occurred. Journal of Memory and Language, 35, 261-285.

Read, J. D. (1996). From a passing thought to a false memory in 2 minutes: Confusing real and illusory events. Psychonomic Bulletin and Review, 3, 105-111.

Reinitz, M. T., Verfaellie, M., \& Milberg, W. P. (1996). Memory conjunction errors in normal and amnesic subjects. Journal of Memory and Language, 35, 286-299.

Reyna, V. F., \& Brainerd, C. J. (1995). Fuzzy-trace theory: An interim synthesis. Learning and Individual Differences. 7 , $1-75$.

Robinson, K. J., \& Roediger, H. L., III. (1997). Associative processes in false recall and false recognition. Psychological Science, 8, 231-237.

Roediger, H. L., III. (1996). Memory illusions. Journal of Memorv and Lanquage. 35, 76-100.

Roediger, H. L., III, \& McDermott, K. B. (1995). Creating false memories: Remembering words not presented in lists. Journal of Experimental Psychology: Learning. Memory. and Cognition, 21, 803-814.

Rosenthal, R. \& Rosnow, R. L. (1985). Contrast Analysis. Cambridge, England: Cambridge University Press.

Rugg, M. D., Fletcher, P. C., Frith, C. D., Frackowiak, R. S. J., \& Dolan, R. J. (1996). Differential activation of the prefrontal cortex in successful and unsuccessful memory retrieval. Brain. 119, 2073-2083.

Schacter, D. L. (1987). Memory, amnesia, and frontal lobe dysfunction. Psychobiology, 15, 21-36.

Schacter, D. L. (1995). Memory distortion: History and current status. In D. L. Schacter, J. T. Coyle, G. D. Fischbach, M.-M. Mesulam, \& L. E. Sullivan (Eds.), Memory distortion: How minds, brains, and societies reconstruct the past (pp. 1-43). Cambridge, MA: Harvard University Press.

Schacter, D. L., Alpert, N. M., Savage, C. R., Rauch, S. L., \& Albert, M. S. (1996). Conscious recollection and the human hippocampal formation: Evidence from positron emission tomography. Proceedings of the National Academy of Sciences, 93, 321-325.

Schacter, D. L., Buckner, R. L., Koutstaal, W., Dale, A. M., \& Rosen, B. R. (1997). Late onset of anterior prefrontal activity during true and false recognition: An event-related fMRI study. NeuroImage, 6, 259-269.

Schacter, D. L., Curran, T., Galluccio, L., Milberg, W., \& Bates, J. (1996). False recognition and the right frontal lobe: A case study. Neuropsychologia. 34, 793-808.

Schacter, D. L., Harbluk, J. L., \& McLachlan, D. R. (1984). Re- trieval without recollection: An experimental analysis of source amnesia. Journal of Verbal Learning and Verbal Behavior, 23, 593-611.

Schacter, D. L., Koutstaal, W., \& Norman, K. A. (1997). False memories and aging. Trends in Cognitive Science, 1, 229236.

Schacter, D. L., Norman, K. A., \& Koutstaal, W. (1998). The cognitive neuroscience of constructive memory. Annual Review of Psychology. 49, 289-318.

Schacter, D. L., Reiman, E., Curran, T., Yun, L. S., Bandy, D., McDermott, K. B., \& Roediger, H. L., III. (1996).

Neuroanatomical correlates of veridical and illusory recognition memory: Evidence from positron emission tomography. Neuron, 17, 267-274.

Schacter, D. L., Verfaellie, M., \& Anes, M. D. (1997). Illusory memories in amnesic patients: Conceptual and perceptual false recognition. Neuropsychology 11, 331-342.

Schacter, D. L., Verfaellie, M., \& Pradere, D. (1996). The neuropsychology of memory illusions: False recall and recognition in amnesic patients. Journal of Memory and Language. 35, 319-334.

Shallice, T. (1988). From neuropsychology to mental structure. Cambridge, England: Cambridge University Press.

Shallice, T., Fletcher, P., Frith, C. D., Grasby, P., Frackowiak, R. S. J., \& Dolan, R. J. (1994). Brain regions associated with acquisition and retrieval of verbal episodic memory. $\mathrm{Na}$ ture, 368, 633-635.

Shimamura, A. P. (1995). Memory and frontal lobe function. In M. Gazzaniga (Ed.), The cognitive neurosciences (pp. 803-813). Cambridge, MA: MIT Press.

Snodgrass, J. G., \& Corwin, J. (1988). Pragmatics of measuring recognition memory: Applications to dementia and amnesia. Journal of Experimental Psychology: General. 117, 34-50.

Squire, L. R. (1982). Comparisons between forms of amnesia: Some deficits are unique to Korsakoff's syndrome. Journal of Experimental Psychology: Learning, Memory. E Cognition, 8, 560-571.

Squire, L. R. (1994). Declarative and nondeclarative memory: Multiple brain systems supporting learning and memory. In D. L. Schacter \& E. Tulving (Eds.), Memory systems 1994 (pp. 203-231). Cambridge, MA: MIT Press.

Stadler, M., Roediger, H. L., III, \& McDermott, K. B. (in press) Norms for word lists that create false memories. Memory and Cognition.

Tulving, E., Kapur, S., Craik, F. I. M., Moscovitch, M., \& Houle, S. (1994). Hemispheric encoding/retrieval asymmetry in episodic memory: Positron emission tomography findings. Proceedings of the National Academv of Sciences. 91, 2016-2020.

Tulving, E., \& Thomson, D. M. (1973). Encoding specificity and retrieval processes in episodic memory. Psychological Review, 80, 352-373.

Tussing, A. A., \& Green, R. L. (1998). False recognition of associates: How robust is the effect? Psychonomic Bulletin \& Review, 4, 572-576.

Underwood, B. J. (1965). False recognition produced by implicit verbal responses. Iournal of Experimental Psychologv, 70, 122-129.

Wilding, E. L., \& Rugg, M. D. (1996). An event-related potential study of recognition memory with and without retrieval of source. Brain, 119, 889-905. 
This article has been cited by:

1. KATJA BRUECKNER, STEFFEN MORITZ. 2009. Emotional valence and semantic relatedness differentially influence false recognition in mild cognitive impairment, Alzheimer's disease, and healthy elderly. Journal of the International Neuropsychological Society 15:02, 268. [CrossRef]

2. MIEKE VERFAELLIE, SUPARNA RAJARAM, KAREN FOSSUM, LISA WILLIAMS. 2008. Not all repetition is alike: Different benefits of repetition in amnesia and normal memory. Journal of the International Neuropsychological Society 14:03. . [CrossRef]

3. Paula Carneiro, Pedro Albuquerque, Angel Fernandez, Francisco Esteves. 2007. Analyzing False Memories in Children With Associative Lists Specific for Their Age. Child Development 78:4, 1171-1185. [CrossRef]

4. Jason P. Mitchell, Alison L. Sullivan, Daniel L. Schacter, Andrew E. Budson. 2006. Misattribution errors in Alzheimer's disease: The illusory truth effect. Neuropsychology 20:2, 185-192. [CrossRef]

5. Andrew E. Budson, Daniel B. J. Droller, Chad S. Dodson, Daniel L. Schacter , Michael D. Rugg, Philip J. Holcomb , Kirk R. Daffner . 2005. Electrophysiological Dissociation of Picture Versus Word Encoding: The Distinctiveness Heuristic as a Retrieval OrientationElectrophysiological Dissociation of Picture Versus Word Encoding: The Distinctiveness Heuristic as a Retrieval Orientation. Journal of Cognitive Neuroscience 17:8, 1181-1193. [Abstract] [PDF] [PDF Plus]

6. Benton H. Pierce, Alison L. Sullivan, Daniel L. Schacter, Andrew E. Budson. 2005. Comparing Source-Based and Gist-Based False Recognition in Aging and Alzheimer's Disease. Neuropsychology 19:4, 411-419. [CrossRef]

7. Andrew E. Budson, Chad S. Dodson, Kirk R. Daffner, Daniel L. Schacter. 2005. Metacognition and False Recognition in Alzheimer's Disease: Further Exploration of the Distinctiveness Heuristic. Neuropsychology 19:2, 253-258. [CrossRef]

8. Doreen Nessler, David Friedman, Michael Bersick. 2004. Classic and false memory designs: An electrophysiological comparison. Psychophysiology 41:5, 679-687. [CrossRef]

9. David A. Gallo, Alison L. Sullivan, Kirk R. Daffner, Daniel L. Schacter, Andrew E. Budson. 2004. Associative Recognition in Alzheimer's Disease: Evidence for Impaired Recall-to-Reject. Neuropsychology 18:3, 556-563. [CrossRef]

10. Steffen Moritz, Todd S. Woodward, Carrie Cuttler, Jennifer C. Whitman, Jason M. Watson. 2004. False Memories in Schizophrenia. Neuropsychology 18:2, 276-283. [CrossRef]

11.STUART J. McKELVIE. 2004. FALSE RECOGNITION WITH DEESE-ROEDIGER-McDERMOTT-REID-SOLSO PROCEDURE: A QUANTITATIVE SUMMARY. Perceptual and Motor Skills 98:3, 1387. [CrossRef]

12. Mieke Verfaellie, Steven Z. Rapcsak, Margaret M. Keane, Michael P. Alexander. 2004. Elevated False Recognition in Patients With Frontal Lobe Damage Is Neither a General Nor a Unitary Phenomenon. Neuropsychology 18:1, 94-103. [CrossRef]

13. Rachel E. Goldmann, Alison L. Sullivan, Daniel B. J. Droller, Michael D. Rugg, Tim Curran, Philip J. Holcomb, Daniel L. Schacter, Kirk R. Daffner, Andrew E. Budson. 2003. Late frontal brain potentials distinguish true and false recognition. NeuroReport 14:13, 1717-1720. [CrossRef]

14. Andrew E. Budson, Kalina J. Michalska, Alison L. Sullivan, Dorene M. Rentz, Kirk R. Daffner, Daniel L. Schacter. 2003. False Recognition in Alzheimer Disease: Evidence from Categorized Pictures. Cognitive and Behavioral Neurology 16:1, 16-27. [CrossRef]

15. JOHN G. SEAMON. 2002. ACCURATE AND FALSE RECALL IN THE DEESE/ROEDIGER AND McDERMOTT PROCEDURE: A METHODOLOGICAL NOTE ON SEX OF PARTICIPANT. Psychological Reports 91:6, 423. [CrossRef]

16. Andrew E. Budson, Joanne Sitarski, Kirk R. Daffner, Daniel L. Schacter. 2002. False recognition of pictures versus words in Alzheimer's disease: The distinctiveness heuristic. Neuropsychology 16:2, 163-173. [CrossRef]

17. Tim Curran, Daniel L. Schacter, Marcia K. Johnson, Ruth Spinks. 2001. Brain Potentials Reflect Behavioral Differences in True and False RecognitionBrain Potentials Reflect Behavioral Differences in True and False Recognition. Journal of Cognitive Neuroscience 13:2, 201-216. [Abstract] [PDF] [PDF Plus]

18. Andrew E. Budson, Rahul Desikan, Kirk R. Daffner, Daniel L. Schacter. 2001. Perceptual false recognition in Alzheimer's disease. Neuropsychology 15:2, 230-243. [CrossRef]

19. Kelly Sullivan Giovanello, Mieke Verfaellie. 2001. The relationship between recall and recognition in amnesia: Effects of matching recognition between patients with amnesia and controls. Neuropsychology 15:4, 444-451. [CrossRef]

20. Carolyn Zerbe Enns. 2001. Some reflections on imagery and psychotherapy implications. Journal of Counseling Psychology 48:2, 136-139. [CrossRef]

21. Erin G. Kitchener, Larry R. Squire. 2000. Impaired verbal category learning in amnesia. Bebavioral Neuroscience 114:5, 907-911. [CrossRef] 
22. Susan A. Clancy, Richard J. McNally, Daniel L. Schacter. 1999. Effects of guided imagery on memory distortion in women reporting recovered memories of childhood sexual abuse. Journal of Traumatic Stress 12:4, 559-569. [CrossRef] 